\title{
Bruton's Tyrosine Kinase: Structure and Functions, Expression and Mutations
}

\section{Ying Liu' ${ }^{*}$, Guang-biao Zhou ${ }^{2}$, Bo Zhang ${ }^{3}$ and Yong-qiang Liu}

${ }^{1}$ The Shenzhen Key Lab of Gene and Antibody Therapy, Center for Biotech \& BioMedicine and Division of Life Sciences, Graduate School at Shenzhen, Tsinghua University, Guangdong, China

${ }^{2}$ Division of Molecular Carcinogenesis and Targeted Therapy for Cancer, State Key Laboratory of Biomembrane and Membrane Biotechnology, Institute of Zoology, Chinese Academy of Sciences, China

${ }^{3}$ National Laboratory of Biomacromolecules, Institute of Biophysics, Chinese Academy of Sciences, China

\begin{abstract}
Bruton's tyrosine kinase (BTK), a member of the Tec family of protein tyrosine kinases (PTKs), plays a vital and diverse function in many cellular processes. BTK is expressed throughout B cell development, widely participating in multiple signal pathways including PI3K, PLCy, and PKC. Those pathways play critical functions in cell proliferation, development, differentiation, survival, and apoptosis. The expression of BTK is selectively down-regulated in T lymphocytes and plasma cells and the relative level of BTK expression may be modulated in different developmental populations of $B$ cells. Mutations in the gene for BTK are responsible for X-linked agammaglobulinemia (XLA) in human and X-inked immunodeficiency (xid) in mice. Both of these diseases are characterized by blocks in B-cell development at multiple stages and impaired function of residual mature B cells. To date, more than 1252 mutations have been identified in human BTK gene associating with XLA. Targeting BTK has achieved remarkable efficacy in $\mathrm{B}$ cell malignancies, multiple myeloma and related bone disease. The present review discusses the recent data regarding the role of BTK in B cell development and its structure, regulation, functions, expression and mutations.
\end{abstract}

Keywords: Bruton's tyrosine kinase; B cells; Function; Expression; Mutation

\section{Introduction}

Non-receptor protein tyrosine kinases are targets in the treatment of a number of diseases. Increasing evidence suggests that these kinases serve multiple roles in diversifying and amplifying the signals emanating from receptors located on the cell surface $[1,2]$. The Tec family formed by BTK, BMX, ITK, TEC, and RLK, are the second largest group of nonreceptor tyrosine kinases $[3,4]$. Functionally, Tec kinases play pivotal roles in the development and signaling of hematopoietic cells $[3,5]$, and are characterized by a common domain organization: from the aminoterminus, there are the pleckstrin homology $(\mathrm{PH})$, Tec homology (TH), Src homology 3 (SH3), SH2, and SH1 domains, especially the SH1 domain, which is also the catalytic domain [6,7]. The unique domain and myristoylation site (and frequently palmitoylation site) are generally found in Src family kinases but not in Tec family kinases. Moreover, Tec family kinases lack the $\mathrm{C}$-terminal regulatory tyrosine residue characteristic of Src [8]. TEC, BTK, ITK, and BMX contain PH domains, which inducibly recruit these kinases to the plasma membrane by binding the phosphatidylinositol-3-kinase (PI3K) product phophatidylinositol3,4,5-triphosphate (PIP3), thereby promoting their activation [9]. While RLK contains a distinct $\mathrm{N}$-terminal cysteine string motif that facilitates palmitoylation and consequent association with lipid rafts $[10,11]$. The TH domain contains several SH3-binding, proline-rich sequences (PXPPXP) shared by this kinase family, with the exception of BMX. The presence of PXXP motif and the SH3 domain establishes an intra-molecular interaction which folds the Tec family kinases in a "closed" form and subject the kinases to regulation by stimuli which activate molecules or ligands that disrupt this interaction $[12,13]$ (Figure 1). Bruton's tyrosine kinase (BTK) is by far the most studied member of Tec family and is mainly expressed in B cells [14]. In addition, it is also expressed in myeloid, mast cells [15,16]. BTK is expressed throughout the development of B cell and is not expressed in T cells and other non-hematopoietic cell linages [17]. In 1993, several research groups discovered the new tyrosine kinase, BTK, which is mutated in a human X-linked agammaglobulinemia (XLA), as known as Bruton's disease. This was the first evidence for the involvement of a protein tyrosine kinase related to the Src-family of oncogenic proteins in a human genetic disease. BTK is also mutated in the mouse X-linked immunodeficiency (xid). It was subsequently recognized that BTK is a member of the Tec family kinases [18-20]. This review will cover the structure, functions, expression, and mutations of BTK.

\section{Structure and functions of BTK}

The BTK gene was mapped to the X-chromosome at Xq21.3Xq22, consisting of 19 exons, spreading $37.5 \mathrm{~kb} .18$ of the 19 exons code for a $77 \mathrm{kDa}$ protein, 659 residues long [21]. As a member of the Tec non-receptor tyrosine kinases family, BTK is also comprised of five domains: $\mathrm{PH}, \mathrm{TH}, \mathrm{SH} 3, \mathrm{SH} 2$, and SH1 [22]. These domains bind different interaction partners (cytosolic proteins or transcription factors) respectively and equip BTK with a critical role in multiple hematopoietic signaling pathways (Figure 2). Hematopoietic signaling pathways including the $\mathrm{B}$ cell antigen receptor (BCR), several cytokine receptors, and heterotrimeric $G$ protein associated receptor signaling $[23,24]$. These signal pathways are transmitted by growth factor receptors, cytokine receptors, G-protein receptors, antigen receptors and integrins [22]. In addition, BTK is regulated by some non-receptor tyrosine kinases, such as JAK, SYK, LYN and FAK family kinases. In turn, BTK regulate many vital signal pathways including those PI3K, PLC $\gamma$, and PKC. Those pathways play critical functions in cell proliferation, development, differentiation, survival, and apoptosis $[2,25,26]$.

*Corresponding author: Ying Liu, The Shenzhen Key Lab of Gene and Antibody Therapy, Center for Biotech \& BioMedicine and Division of Life Sciences, Graduate School at Shenzhen, Tsinghua University, Shenzhen, 518055, Guangdong, China, Tel: 86-755-26036012, Fax: 86-755-26036012; E-mail: liu.ying2012@sz.tsinghua.edu.cn

Received October 11, 2013; Accepted November 15, 2013; Published November 18,2013

Citation: Liu Y, Zhou G, Zhang B, Liu Y (2013) Bruton's Tyrosine Kinase: Structure and Functions, Expression and Mutations. Gene Technology 2: 106. doi: 10.4172/2329-6682.1000106

Copyright: (c) 2013 Liu Y, et al. This is an open-access article distributed under the terms of the Creative Commons Attribution License, which permits unrestricted use, distribution, and reproduction in any medium, provided the original author and source are credited. 


\begin{tabular}{|c|c|c|c|c|c|c|}
\hline $\mathrm{FH}$ & 8тк T & PRR & $\mathrm{SH} 3$ & $\mathrm{SH} 2$ & $\mathrm{SH} 1$ & BTK, TEC, ITK \\
\hline & $\operatorname{cccc}$ & PRR & $\mathrm{SH} 3$ & SH2 & $\mathrm{SH} 1$ & RLK \\
\hline & $\mathrm{PH}$ & втк & $\mathrm{SH} 3$ & $\mathrm{SH} 2$ & $\mathrm{SH} 1$ & BMX \\
\hline
\end{tabular}

Figure 1: Molecular structures of the Tec family kinases.

$\mathrm{PH}$ refers to pleckstrin homology domain, $\mathrm{SH} 3$ to Src homology domain 3, $\mathrm{SH} 2$ to Src homology domain 2, and $\mathrm{SH} 1$ to Src homology domain 1 (catalytic domain). CCCCC refers to cysteine-string motif. TH refers to Tec homology, containing BTK motif and PRR (proline-rich region)

Its expression throughout B cell development, BTK plays critical functions in B cell proliferation, development, differentiation, survival, and apoptosis [27]. In BCR singal pathway, following antigen binding of $\mathrm{BCR}$, the cytoplasmic tails of $\operatorname{Ig} \alpha / \operatorname{Ig} \beta$ Heterodimers are phosphorylated by Src family members [28]. Then the phosphorylation sites act as docking sites for BTK. Following the PH domain binding of PIP3, BTK is targeted to the membrane. The Y551 site is then transphosphorylated by Src family tyrosine kinases. The next step is BTK auto-phosphorylation itself on Y223 residue in the SH3 domain. Then BTK begins to transmit signals [23]. Previous reports have indicated that BTK participate in G-protein signal pathway through directly binding different subunits of G-proteins, and then is activated by subunits of heterotrimeric $G$ proteins, such as G $\beta \gamma$, Gqa., and Ga12 $[29,30]$. Then the G protein-regulated PI3K $\gamma$, isoform of PI3 kinase, can induce phosphorylation of BTK and dramatically enhance the ability of BTK to transmit signals in an ectopic over-expression system $[31,32]$. However, whether BTK-dependent, G-protein coupled receptorinitiated signals are important during $B$ cell development remains to be determined [33,34]. In addition to its function in pre-BCR signaling, BTK has been implicated as a mediator of signals from various other receptors, including FceR, IL-5R, IL-6R, IL-10R, collagen receptor, erythropoietin receptor, and Toll-like receptor 4 [35-39]. IL-6 was showing to activate BTK in B lymphocytes. Stable complexes were formed by activated IL- 6 receptors via JAK family kinases with BTK. Then through this association BTK is phosphorylated by JAK $[2,40]$. BTK widely participates in multiple downstream signal pathways. And the well-studied downstream signal is perhaps the PLC $\gamma$ and PKC $\beta$, with a side induction of sustained calcium influx [41] and final MAPK/ JNK activation [42]. In PLC $\gamma$ signal, phosphorylated BTK recruits the adapter B-cell linker protein (BLNK) [also known as SH2 domaincontaining leukocyte specific phosphoprotein of $65 \mathrm{kDa}$ (SLP-65)] together with PLC $\gamma 2$ to the plasma membrane, bringing them in close to Syk, Syk activation results in phosphorylation of BLNK, recruitment and activation of PLC $\gamma 2$ leading to IP3 production, and release of calcium from the ER calcium store [26,43]. Accident P13K activiation leads to production of phophatidylinositol3,4,5-triphosphate (PIP3) and diacylglycerol (DAG), causing calcium mobilization and $\mathrm{PKC} \beta$ activation, respectively $[23,44]$. In addition, BTK can also mediate BCR-stimulated calcium influx [32] and B cell development [45] independently of its catalytic activity. Acting as an adaptor, BTK recruits and activates phosphatidylinositol 4-phosphate 5-kinase (PIP5K) [32], which produces the substrate for PLC $\gamma 2$. Thus, BTK signals through PLC $\gamma 2$ directly, by phosphorylation, and indirectly, by increasing substrate availability [46]. The secondary messenger IP3 mediates the opening of intracellular calcium stores, which subsequently activates
PKC $\beta$. Then activated PKC $\beta$ phosphorylates IKB kinase $\alpha$ and thereby induces NF- $\kappa B$ activation, following by up-regulation of the antiapoptotic protein Bcl-xl and cyclin D2 [34,47-49] (Figure 3).

\section{BTK in B cell development}

BTK is expressed throughout B cell development. It sustains the developmental program of pre- $B$ cells by limiting the pre- $B$ cell expansion and by promoting B-cell differentiation. The levels of BTK keep constant at all stages of $\mathrm{B}$ cell development in the bone marrow but drop significantly as cells enter the periphery [14,17]. XLA is characterized by a severe block in B cell development at the pre-B cell stage while xid have normal number of pre-B and immature $B$ cells [50,51]. In addition, the xid cells compared to normal cells have a competitive disadvantage at the pre-B to immature transition [52]. Thus, BTK does contribute to the early stages of B cell development. A dual role for BTK in B cell survival and functional responses is also supported by a BTK transgenic mouse model. In xid and BTK-/- mice, splenic B cells transgene expressing wild type BTK protein at $25 \%$ of endogenous levels can completely restores conventional B cell development [53]. Responses to TNP-Ficoll in vivo and BCR crosslinking in vitro are above those of xid mice but remain significantly impaired relative to wild type controls. Wild-type BTK protein levels two fold increase in obtained by generating mice homozygous for the transgene results in four fold greater response to both TNP-Ficoll and anti-IgM as well as increased sensitivity to $\mathrm{BCR}$ cross linking. The above observations indicate that the dosage of BTK is limiting for BCR signaling and that there is a higher threshold level of BTK required for B cell functional than for responses survival $[53,54]$. Thus, the sensitivity of $B$ cell function to BTK levels suggests that BTK may be an attractive therapeutic target for diseases involving hyperactive B cells, such as autoimmunity.

\section{Expression of BTK}

The Tec family kinases, are widely expressed in a wide range of vertebrate tissues [2]. In mammals, Tec kinases are expressed prominently in hematopoietic cells where they are expressed with a relatively high degree of lineage specificity $[55,56]$. TEC and BMX are expressed ubiquitously. B cells express primarily BTK while T cells express both ITK and RLK [57]. In addition, besides expression in hematopoietic tissues, Tec kinase family members were also reported in liver, kidney, heart, lung and ovarian tissues [58, 59]. BTK is expressed at all stages of $\mathrm{B}$ lineage development from $\mathrm{CD} 34+$ pro- $\mathrm{B}$ to mature $B$ cells while is down-regulated in plasma $B$ cells $[19,60,61]$. Previous studies reported that the relative level of BTK expression may be modulated in different developmental populations. In surface of

\begin{tabular}{|c|c|c|c|c|}
\hline $\mathrm{PH}$ & BTK TH PRR & $\mathrm{SH} 3$ & $\mathrm{SH} 2$ & $\mathrm{SH} 1$ \\
\hline $140 \mathrm{AA}$ & $25 \mathrm{AA} \quad 50 \mathrm{AA}$ & $65 \mathrm{AA}$ & $100 \mathrm{AA}$ & $280 \mathrm{AA}$ \\
\hline PIP3 & $G_{\beta \gamma}$ & $c-c b l$ & BLNK & $G_{B \gamma}$ \\
\hline$G_{B V}$ & $G_{00}$ & WASP & & Fas \\
\hline TF II - I & Lyn & Sab & & \\
\hline \multicolumn{2}{|r|}{ Fvn } & & & \\
\hline
\end{tabular}

Figure 2: Schematic model of BTK showing different domains and interacting molecules.

The TH domain contains BTK motif and PRR (proline-rich region). The pY223 and pY551 are phosphorylation sites. Interaction partners are showing in blue. PIP3: phosphatidylinositol 3, 4, 5-trisphosphate; WASP: WiscottAldrich syndrome protein; BLNK: B-cell linker protein; TFII: transcription factor II. 


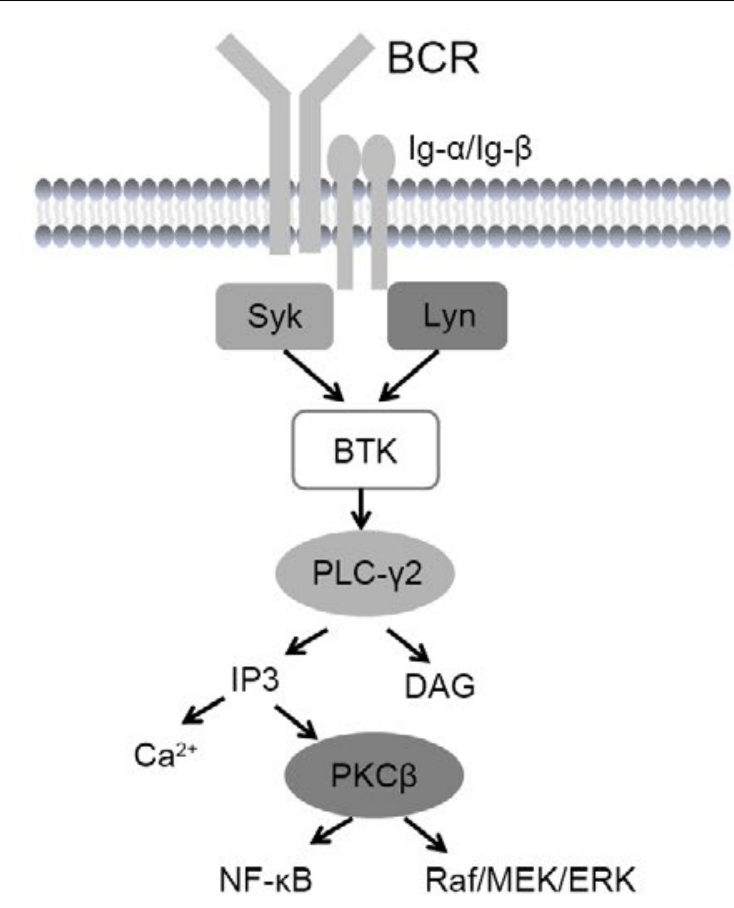

Figure 3: Signaling pathways upstream/downstream of BTK.

IgM $\mathrm{M}^{\mathrm{hi}}$ immature B cells, the expression of BTK is considerably higher than in mature IgMlo IgDhi splenic B cells [62]. Bone marrow B cells have 3-10-fold more BTK than splenic B cells. In XLA, which contain specific phenotype B lineage, BTK is found to express in myeloid cells, erythroid precursors, mast cells, but not NK and T lineages [63]. XLA is a partial block between the pro- and pre-B cell stage and the virtual absence of B lymphocytes. On the contrary, both xid mice and BTK/-mice have normal numbers of pre-B and immature B cells. These observations suggest that BTK dosage must be tightly regulated during B lymphopoiesis. Indeed, BTK levels remain constant at all stages of B cell development in the bone marrow but drop significantly as cells enter the periphery. Recent studies indicate that a novel function of truncated kinase-inactive BTK was identified in human BCR-ABL1+ pre- $B$ cell leukemia cells. In these diseases, BCR-ABL1 induces aberrant splicing of BTK, resulting in the presence of BTK-p52 (lack of exon 15, loss of reading frame) and BTK-p62 (in frame deletions of exons 15 and 16) isoforms. Kinase-deficient splice variants are co-expressed with fulllength BTK, acting as a dominant-negative BTK in that they suppress BTK-dependent differentiation and pre-B cell receptor responsiveness of the leukemia cells $[64,65]$. Thus, BTK activity represents an obvious target to be considered for therapeutic intervention in BCR-ABL1+ pre-B cell leukemia. Except for expressing in B lineage, myeloid, and mast cells, BTK also expressed in macrophages, and neutrophils [34]. Recent findings from our institute demonstrate that BTK is elevated and activated in dexamethasone-resistant multiple myeloma (MM) cell line and 2 out of $9(22.2 \%)$ MM patients' cells. Interestingly, patients with higher BTK expression have poorer prognosis [56].

\section{Mutations in BTK}

To date, the only Tec kinase known to cause human disease is BTK. X-linked agammaglobulinemia (XLA) is the proto typic humoral immunodeficiency described in 1952 by Bruton [66,67]. This hereditary immunodeficiency disease is caused by arrest in early B-cell differentiation and is characterized by recurrent bacterial infections and profound hypogammaglobulinemia with marked reduction or lack of mature B-cells in the peripheral blood $[19,20]$. Thus, patients with XLA are clinically characterized by a pronounced reduction in serum immunoglobulins therefore suffer from recurrent bacterial and enteroviral infections [68]. In mice, functional B lymphocytes, also reduced in numbers. But xid mice exhibit a less severe phenotype than that of patients with XLA [69,70]. In 1993, several research groups reported mutations in the gene encoding BTK associating to XLA in human and xid in mice. A range of biochemical and functional studies indicate that BTK deficiency interferes with B lineage-specific signal transduction pathways critical for both early $B$ lineage growth and clonal expansion and mature B lineage survival and activation. And previous studies indicated that $90-95 \%$ of males with presumed XLA have mutations in BTK [71]. To date more than 1252 different mutations have been identified. These mutations are listed in BTKbase, a XLA mutation registry, which was established in 1994 (http://bioinf. uta.fi/BTKbase/; last update 24 Oct., 2012). The mutations overlay all the domains of BTK, as well as in non-coding sequences. Mutation types consist of Missense mutations (40\%), small insertions and deletions (27\%), Splice-site mutations (16\%), nonsense mutations (17\%) [72]. However, as far as is known, no overt genotype-phenotype correlation, probably due to the fact that almost all patients analyzed belong to the group with classical (severe) disease. In the mouse, BTK gene inactivated causes a mild phenotype resembling the spontaneous xid mutant carrying the missense mutation R28C in the $\mathrm{PH}$ domain. These mice lack B-1 cells, reducing to $30-50 \%$ of the normal numbers, have reduced numbers of spleen $B$ cells and show decreased levels of IgM and IgG3 $[18,73,74]$. Thus, the phenotype of mutated mice is still considerably milder than that of affected humans, who essentially lack B lymphocytes and immunoglobulins, irrespective of the type of mutation. Our institute screened for sequence variations of coding sequence of BTK gene by $\mathrm{cDNA}$ sequencing in MM cell lines and 8 unrelated patients. The sequencing results showed that 6 out 8 patients (75\%) carried a SNP at position 2062 (T2062C) in BTK gene coding domain [56]. Although this SNP does not alter the coding amino acid of the codon, it appears to be common in MM, and possibly MM-specific. Therefore, the function of BTK in MM warrants further investigation.

\section{Therapeutic Potential of Inhibiting BTK}

Functional abnormalities of PTKs have been described by previous reports in cancer, immunodeficiency, diabetes, arteriosclerosis and psoriasis [74]. And the therapeutic potential targeting BTK or upstream/downstream effectors associated with BTK were proposed and has achieved remarkable efficacy with an acceptable safety profile in B cell malignancies by lots of scientists $[14,49,74]$. The antiapoptosis function of BTK is supported by the observation that $b c l-2$ and $b c l-x l$ trangenes can restore normal B cell levels in xid mice [54]. Furthermore, BTK can induce Bcl-xl expression and inhibits the proapoptotic effects of Fas ligation in mature B cells [51]. Due to the vital role of BTK in hematopoiesis of B cells, several reports suggested that alteration of its function would cause various diseases associated with abnormal development of B cells $[34,49]$. So in the past ten years, a number of researches have addressed the possible functions of BTK in blood cancer development $[14,15,49,56,74]$. Ibrutinib, an orally available inhibitor which irreversibly and selectively binds to BTK, has achieved high response rates in phase I/II clinical trials in relapsed non Hodgkin's lymphoma, and phase III clinial trials in mantle cell lymphoma and chronic lymphocytic leukaemia [73,74]. In addition, Tai et al. [14] found that Ibrutinib not only targets MM tumor cells but also bone marrow microenvironment that support MM cell growth and survival, as well as MM-deteriorated bone lysis. These results 
Citation: Liu Y, Zhou G, Zhang B, Liu Y (2013) Bruton's Tyrosine Kinase: Structure and Functions, Expression and Mutations. Gene Technology 2: 106. doi: $10.4172 / 2329-6682.1000106$

Page 4 of 5

demonstrate BTK inhibitors are extremely attractive approach not only for B-cell malignancies, but also for myeloma and related bone disease.

\section{Conclusion}

In conclusion, this review has briefly summarized work defining the structure of BTK, the range of signaling pathways potentially utilizing BTK, and the mutations leading to altered BTK function. In addition, we have discussed several aspects on the biology of BTK, and the specific expressional pattern of BTK. As a highly conserved nonreceptor tyrosine kinase, through interacting with diverse interaction partners, BTK plays diverse roles in different species. Although in the last decade quite a lot has been learned about the events related to BCR signaling, the precise role of BTK in this pathway remains poorly understood. Although large numbers of mutations have been assembled in the BTKbase in the last decade, there is no evidence for a correlation between the type and position of a mutation and phenotypic parameters as age at clinical onset, serum immunoglobulin levels at onset of the disease, or the severity of infections encountered. BTK is expressed in high levels in cells of the B lymphoyte and myeloid lineages and also in mast cell leukemia line, whereas low or undetectable levels were found in T cells and plasma cells. BTK plays multiple roles in the life of a B cell. It is important for both survival and proliferative response to antigen and is involved in setting BCR signaling thresholds. Targeting BTK has achieved remarkable efficacy with an acceptable safety profile in B cell malignancies. We therefore believe that this non-receptor tyrosine kinase will continue to play an important role not only for primary immunodeficiencies and B cell malignancies but also for the basic understanding of the development of the immune system and for signal transduction at large.

\section{References}

1. Condorelli F, Stec-Martyna E, Zaborowska J, Felli L, Gemmi I, et al. (2011) Role of the non-receptor tyrosine kinase fes in cancer. Curr Med Chem 18: 2913-2920.

2. Yun Qiu, Hsing-Jien Kung (2000) Signaling network of the Btk family kinases. Oncogene 19:5651-5660.

3. Faris $M$, Bot $A(2012)$ In this issue: Tec kinases in the crosshairs. Int Rev Immunol 31: 85-86.

4. Horwood NJ, Urbaniak AM, Danks L (2012) Tec family kinases in inflammation and disease. Int Rev Immunol 31: 87-103.

5. Schmidt U, Boucheron N, Unger B, Ellmeier W (2004) The role of Tec family kinases in myeloid cells. Int Arch Allergy Immunol 134: 65-78.

6. Conley ME, Fitch-Hilgenberg ME, Cleveland JL, Parolini O, Rohrer J (1994) Screening of genomic DNA to identify mutations in the gene for Bruton's tyrosine kinase. Hum Mol Genet 3: 1751-1756.

7. Readinger JA, Mueller KL, Venegas AM, Horai R, Schwartzberg PL (2009) Tec kinases regulate T-lymphocyte development and function: new insights into the roles of Itk and Rlk/Txk. Immunol Rev 228: 93-114.

8. Yang WC, Collette $Y$, Nunès JA, Olive D (2000) Tec kinases: a family with multiple roles in immunity. Immunity 12: 373-382.

9. Schwartzberg PL, Finkelstein LD, Readinger JA (2005) TEC-family kinases: regulators of T-helper-cell differentiation. Nat Rev Immunol 5: 284-295.

10. Pillai S, Moran ST (2002) Tec kinase pathways in lymphocyte development and transformation. Biochim Biophys Acta 1602: 162-167.

11. Gomez-Rodriguez J, Kraus ZJ, Schwartzberg PL (2011) Tec family kinases Itk and Rlk / Txk in T lymphocytes: cross-regulation of cytokine production and T-cell fates. FEBS J 278: 1980-1989.

12. Sirvent A, Benistant C, Roche S (2012) Oncogenic signaling by tyrosine kinases of the SRC family in advanced colorectal cancer. Am J Cancer Res 2: 357-371.

13. Himpe E, Abdul Rahim SA, Verdood P, Mano H, Kooijman R (2013) Tec kinase stimulates cell survival in transfected Hek293T cells and is regulated by the anti-apoptotic growth factor IGF-I in human neutrophils. Cell Signal 25: 666673
14. Tai YT, Chang BY, Kong SY, Fulciniti M, Yang G, et al. (2012) Bruton tyrosine kinase inhibition is a novel therapeutic strategy targeting tumor in the bone marrow microenvironment in multiple myeloma. Blood 120: 1877-1887.

15. Edwards CM (2012) BTK inhibition in myeloma: targeting the seed and the soil. Blood 120: 1757-1759.

16. Gilfillan AM, Rivera J (2009) The tyrosine kinase network regulating mast cel activation. Immunol Rev 228: 149-169.

17. Smith Cl, Baskin B, Humire-Greiff P, Zhou JN, Olsson PG, et al. (1994) Expression of Bruton's agammaglobulinemia tyrosine kinase gene, BTK, is selectively down-regulated in T lymphocytes and plasma cells. J Immunol 152 557-565.

18. Thomas JD, Sideras $\mathrm{P}$, Smith Cl, Vorechovský I, Chapman V, et al. (1993) Colocalization of $X$-linked agammaglobulinemia and $X$-linked immunodeficiency genes. Science 261: 355-358.

19. Tsukada S, Saffran DC, Rawlings DJ, Parolini O, Allen RC, et al. (1993) Deficient expression of a B cell cytoplasmic tyrosine kinase in human X-linked agammaglobulinemia. Cell 72: 279-290.

20. Vetrie D, Vorechovský I, Sideras P, Holland J, Davies A, et al. (1993) The gene involved in X-linked agammaglobulinaemia is a member of the src family of protein-tyrosine kinases. Nature 361: 226-233.

21. Rawlings DJ (1999) Bruton's tyrosine kinase controls a sustained calcium signal essential for B lineage development and function. Clin Immunol 91: 243-253.

22. Gustafsson MO, Hussain A, Mohammad DK, Mohamed AJ, Nguyen V, et al. (2012) Regulation of nucleocytoplasmic shuttling of Bruton's tyrosine kinase (Btk) through a novel SH3-dependent interaction with ankyrin repeat domain 54 (ANKRD54). Mol Cell Biol 32: 2440-2453.

23. Lindvall JM, Blomberg KE, Väliaho J, Vargas L, Heinonen JE, et al. (2005) Bruton's tyrosine kinase: cell biology, sequence conservation, mutation spectrum, siRNA modifications, and expression profiling. Immunol Rev 203 200-215.

24. Kil LP, de Bruijn MJ, van Hulst JA, Langerak AW, Yuvaraj S, et al. (2013) Bruton's tyrosine kinase mediated signaling enhances leukemogenesis in mouse model for chronic lymphocytic leukemia. Am J Blood Res 3: 71-83.

25. Vassilev AO, Uckun FM (2004) Therapeutic potential of inhibiting Bruton's tyrosine kinase, (BTK). Curr Pharm Des 10: 1757-1766.

26. Ying H, Li Z, Yang L, Zhang J (2011) Syk mediates BCR- and CD40-signaling integration during B cell activation. Immunobiology 216: 566-570.

27. Lee KG, Xu S, Wong ET, Tergaonkar V, Lam KP (2008) Bruton's tyrosine kinase separately regulates NFkappaB p65RelA activation and cytokine interleukin (IL)-10/IL-12 production in TLR9-stimulated B Cells. J Biol Chem 283: $11189-11198$

28. Liu Z, Mai A, Sun J (2010) Lysine acetylation regulates Bruton's tyrosine kinase in B cell activation. J Immunol 184: 244-254

29. Bence K, Ma W, Kozasa T, Huang XY (1997) Direct stimulation of Bruton's tyrosine kinase by G(q)-protein alpha-subunit. Nature 389: 296-299.

30. Jiang Y, Ma W, Wan Y, Kozasa T, Hattori S, et al. (1998) The G protein G alpha12 stimulates Bruton's tyrosine kinase and a rasGAP through a conserved $\mathrm{PH} / \mathrm{BM}$ domain. Nature 395: 808-813.

31. Li Z, Wahl MI, Eguinoa A, Stephens LR, Hawkins PT, et al. (1997) Phosphatidylinositol 3-kinase-gamma activates Bruton's tyrosine kinase in concert with Src family kinases. Proc Natl Acad Sci U S A 94: 13820-13825.

32. Saito K, Tolias KF, Saci A, Koon HB, Humphries LA, et al. (2003) BTK regulates Ptdlns-4,5-P2 synthesis: importance for calcium signaling and $\mathrm{PI} 3 \mathrm{~K}$ activity. Immunity 19: 669-678.

33. Satterthwaite AB, Witte ON (2000) The role of Bruton's tyrosine kinase in B-cel development and function: a genetic perspective. Immunol Rev 175: 120-127.

34. Janda E, Palmieri C, Pisano A, Pontoriero M, laccino E, et al. (2011) Btk regulation in human and mouse $B$ cells via protein kinase $C$ phosphorylation of IBtk| $\left.\right|^{3}$. Blood 117: 6520-6531.

35. Sochorová K, Horváth R, Rozková D, Litzman J, Bartunková J, et al. (2007) Impaired Toll-like receptor 8-mediated IL-6 and TNF-alpha production in antigen-presenting cells from patients with X-linked agammaglobulinemia. Blood 109: 2553-2556

36. Gutierrez T, Mayeux JM, Ortega SB, Karandikar NJ, Li QZ, et al. (2013) IL-21 promotes the production of anti-DNA IgG but is dispensable for kidney damage in Iyn-/- mice. Eur J Immunol 43: 382-393. 
Citation: Liu Y, Zhou G, Zhang B, Liu Y (2013) Bruton's Tyrosine Kinase: Structure and Functions, Expression and Mutations. Gene Technology 2: 106. doi: $10.4172 / 2329-6682.1000106$

Page 5 of 5

37. Krupa A, Fudala R, Florence JM, Tucker T, Allen TC, et al. (2013) Bruton's tyrosine kinase mediates $\mathrm{FC}^{3} \hat{i}^{3} \mathrm{Rlla} /$ Toll-like receptor-4 receptor crosstalk in human neutrophils. Am J Respir Cell Mol Biol 48: 240-249.

38. Ní Gabhann J, Spence S, Wynne C, Smith S, Byrne JC, et al. (2012) Defects in acute responses to TLR4 in Btk-deficient mice result in impaired dendritic cellinduced IFN-Î ${ }^{3}$ production by natural killer cells. Clin Immunol 142: 373-382.

39. Schmidt NW, Thieu VT, Mann BA, Ahyi AN, Kaplan MH (2006) Bruton's tyrosine kinase is required for TLR-induced IL-10 production. J Immunol 177: 7203-7210.

40. Takahashi-Tezuka M, Hibi M, Fujitani Y, Fukada T, Yamaguchi T, et al. (1997) Tec tyrosine kinase links the cytokine receptors to PI-3 kinase probably through JAK. Oncogene 14: 2273-2282.

41. Xie Q, Joseph RE, Fulton DB, Andreotti AH (2013) Substrate recognition of PLCî̉ 1 via a specific docking surface on Itk. J Mol Biol 425: 683-696.

42. Win S, Than TA, Han D, Petrovic LM, Kaplowitz N (2011) c-Jun N-terminal kinase (JNK)-dependent acute liver injury from acetaminophen or tumo necrosis factor (TNF) requires mitochondrial Sab protein expression in mice. $J$ Biol Chem 286: 35071-35078.

43. Tan SL, Liao C, Lucas MC, Stevenson C, DeMartino JA (2013) Targeting the SYK-BTK axis for the treatment of immunological and hematological disorders: recent progress and therapeutic perspectives. Pharmacol Ther 138: 294-309.

44. Kuehn HS, Swindle EJ, Kim MS, Beaven MA, Metcalfe DD, et al. (2008) The phosphoinositide 3-kinase-dependent activation of Btk is required for optimal eicosanoid production and generation of reactive oxygen species in antigenstimulated mast cells. J Immunol 181: 7706-7712.

45. Middendorp S, Dingjan GM, Maas A, Dahlenborg K, Hendriks RW (2003) Function of Bruton's tyrosine kinase during B cell development is partially independent of its catalytic activity. J Immunol 171: 5988-5996.

46. Halcomb KE, Contreras CM, Hinman RM, Coursey TG, Wright HL, et al. (2007) Btk and phospholipase $\mathrm{C}$ gamma 2 can function independently during $\mathrm{B}$ cell development. Eur J Immunol 37: 1033-1042.

47. Saijo K, Mecklenbräuker I, Santana A, Leitger M, Schmedt C, et al. (2002) Protein kinase $C$ beta controls nuclear factor kappaB activation in $B$ cells through selective regulation of the IkappaB kinase alpha. J Exp Med 195: 16471652 .

48. Suzuki H, Matsuda S, Terauchi Y, Fujiwara M, Ohteki T, et al. (2003) PI3K and Btk differentially regulate $B$ cell antigen receptor-mediated signal transduction. Nat Immunol 4: 280-286.

49. Buggy JJ, Elias L (2012) Bruton tyrosine kinase (BTK) and its role in B-cell malignancy. Int Rev Immunol 31: 119-132.

50. Martini H, Enright V, Perro M, Workman S, Birmelin J, et al. (2011) Importance of B cell co-stimulation in CD4(+) T cell differentiation: X-linked agammaglobulinaemia, a human model. Clin Exp Immunol 164: 381-387.

51. Khare A, Viswanathan B, Gund R, Jain N, Ravindran B, et al. (2011) Role of Bruton's tyrosine kinase in macrophage apoptosis. Apoptosis 16: 334-346.

52. Kerner JD, Appleby MW, Mohr RN, Chien S, Rawlings DJ, et al. (1995) Impaired expansion of mouse B cell progenitors lacking Btk. Immunity 3: 301-312.

53. Satterthwaite AB, Cheroutre H, Khan WN, Sideras P, Witte ON (1997) Btk dosage determines sensitivity to $B$ cell antigen receptor cross-linking. Proc Nat Acad Sci U S A 94: 13152-13157.

54. Satterthwaite AB, Li Z, Witte ON (1998) Btk function in B cell development and response. Semin Immunol 10: 309-316.

55. Bam R, Ling W, Khan S, Pennisi A, Venkateshaiah SU, et al. (2013) Role of Bruton's tyrosine kinase in myeloma cell migration and induction of bone disease. Am J Hematol 88: 463-471.
56. Liu Y, Dong Y, Jiang QL, Zhang B, Hu AM (2013) Bruton's tyrosine kinase: potential target in human multiple myeloma. Leuk Lymphoma.

57. Nayar R, Enos M, Prince A, Shin H, Hemmers S, et al. (2012) TCR signaling via Tec kinase ITK and interferon regulatory factor 4 (IRF4) regulates CD8+ T-cell differentiation. Proc Natl Acad Sci U S A 109: E2794-2802.

58. Rawlings DJ, Witte ON (1995) The Btk subfamily of cytoplasmic tyrosine kinases: structure, regulation and function. Semin Immunol 7: 237-246.

59. de Weers M, Verschuren MC, Kraakman ME, Mensink RG, Schuurman RK et al. (1993) The Bruton's tyrosine kinase gene is expressed throughout B cel differentiation, from early precursor B cell stages preceding immunoglobulin gene rearrangement up to mature B cell stages. Eur J Immunol 23: 3109-3114.

60. Genevier HC, Hinshelwood S, Gaspar HB, Rigley KP, Brown D, et al. (1994) Expression of Bruton's tyrosine kinase protein within the $B$ cell lineage. Eur Immunol 24: 3100-3105.

61. Kersseboom R, Ta VB, Zijlstra AJ, Middendorp S, Jumaa $\mathrm{H}$, et al. (2006) Bruton's tyrosine kinase and SLP-65 regulate pre-B cell differentiation and the induction of Ig light chain gene rearrangement. J Immunol 176: 4543-4552.

62. Feldhahn N, Río P, Soh BN, Liedtke S, Sprangers M, et al. (2005) Deficiency of Bruton's tyrosine kinase in B cell precursor leukemia cells. Proc Natl Acad Sci U S A 102: 13266-13271.

63. Feldhahn N, Klein F, Mooster JL, Hadweh P, Sprangers M, et al. (2005) Mimicry of a constitutively active pre-B cell receptor in acute lymphoblastic leukemia cells. J Exp Med 201: 1837-1852.

64. Bruton OC (1952) Agammaglobulinemia. Pediatrics 9:722-727.

65. BRUTON OC, APT L, GITLIN D, JANEWAY CA (1952) Absence of serum gamma globulins. AMA Am J Dis Child 84: 632-636.

66. Qin X, Jiang LP, Tang XM, Wang M, Liu EM, et al. (2013) Clinical features and mutation analysis of $X$-linked agammaglobulinemia in 20 Chinese patients. World J Pediatr 9: 273-277.

67. Ellmeier W, Jung S, Sunshine MJ, Hatam F, Xu Y, et al. (2000) Severe B cell deficiency in mice lacking the tec kinase family members Tec and Btk. J Exp Med 192: 1611-1624.

68. Conley ME, Mathias D, Treadaway J, Minegishi Y, Rohrer J (1998) Mutations in btk in patients with presumed X-linked agammaglobulinemia. Am J Hum Gene 62: 1034-1043

69. Vargas-Hernández A, López-Herrera G, Maravillas-Montero JL, VencesCatalán F, Mogica-Martínez D, et al. (2012) Consequences of two naturally occurring missense mutations in the structure and function of Bruton agammaglobulinemia tyrosine kinase. IUBMB Life 64: 346-353.

70. Rawlings DJ, Saffran DC, Tsukada S, Largaespada DA, Grimaldi JC, et al. (1993) Mutation of unique region of Bruton's tyrosine kinase in immunodeficient XID mice. Science 261: 358-361.

71. Mohamed AJ, Yu L, Bäckesjö CM, Vargas L, Faryal R, et al. (2009) Bruton's tyrosine kinase (Btk): function, regulation, and transformation with special emphasis on the PH domain. Immunol Rev 228: 58-73.

72. Traxler $P$ (2003) Tyrosine kinases as targets in cancer therapy - successes and failures. Expert Opin Ther Targets 7: 215-234.

73. Hantschel O, Rix U, Schmidt U, Bürckstümmer T, Kneidinger M, et al. (2007) The Btk tyrosine kinase is a major target of the Bcr-Abl inhibitor dasatinib. Proc Natl Acad Sci U S A 104: 13283-13288.

74. Tai YT, Anderson KC (2012) Bruton's tyrosine kinase: oncotarget in myeloma Oncotarget 3: 913-914 